\title{
THE TEMPORAL ROLE OF EASTERN BANTU -ba AND $-1 i^{*}$
}

Robert Botne

Indiana University

\begin{abstract}
In the eastern Bantu languages forms of the verb 'be', -ba and/or $-\mathrm{I} \mathrm{i}$, are commonly employed in complex constructions in which they take sentential(-1ike) complements. Though often considered to be semantically empty in these constructions, they are analyzed here as shifters, having both referential and indexical properties.

As such they function to establish additional parameters to the temporal framework in which the narrated event is to be interpreted.
\end{abstract}

\section{Introduction}

In eastern Bantu languages forms of the verb 'be', -ba and/or - li, are often employed in complex constructions in which they take a sentential(-1ike) complement. In these constructions we commonly find tense/aspect markers both on the matrix verb, i.e. the particular form of 'be', and on the complement verb. One conventional explanation of this phenomenon has been to consider the so-called auxiliary verb 'be' to be a semantically empty support for tense markers, an approach not unlike that of early generativists with respect to the English auxiliary verb 'do'. Another approach has been to state in a vague manner that the time of the event is more specifically asserted. In this paper $I$ want to propose that $-b a$ and $-1 i$, in those languages that utilize them in such complex constructions, are not semantically empty but

* This paper is a revised version of a paper presented at the 16th African Linguistics Conference held at Yale University April 1985. I would like to thank Musomandera Providence (Kinyarwanda), Firmard Sabimana (Kirundi), Mhechela George (Cigogo), and Enoch Mvula (Cinyanja) for being such diligent informants. 
function to establish additional parameters to the temporal framework in which the narrated event is to be interpreted, thereby indicating more precisely the temporal location of the event. More specifically, I will argue that -ba and $-1 \mathrm{i}$ function as shifters, having both referential and indexical properties.

\section{Establishing a Locus of Orientation}

For all languages it would appear that the speech act itself serves to establish the primary locus for temporal orientation. Whatever the particular structure of the tense/aspect system may be, events (as named by verbs) are normally marked and interpreted temporally with respect to the time of the speech event $\left(t_{s p}\right)$ in those languages that grammaticalize tense distinctions. However, it is not the case that languages are restricted to one grammatically relevant locus of orientation. There are at least a few languages which, in addition to the speech event, utilize a second (or even third) event as another locus of orientation for the temporal representation of events, and, more significantly for the present analysis, they refer to and index this eventlocus grammatically.

In effect, the grammaticalization of this second event-locus establishes a second temporal continuum, dependent on the time of the speech event for its proper interpretation. Thus, in those languages that grammaticalize a second locus we find a potential for complex temporal frameworks in which the narrated event is to be interpreted. Such a framework, in which the second locus is situated posterior to the speech event, is schematized in Figure 1.

Figure 1. Complex temporal framework

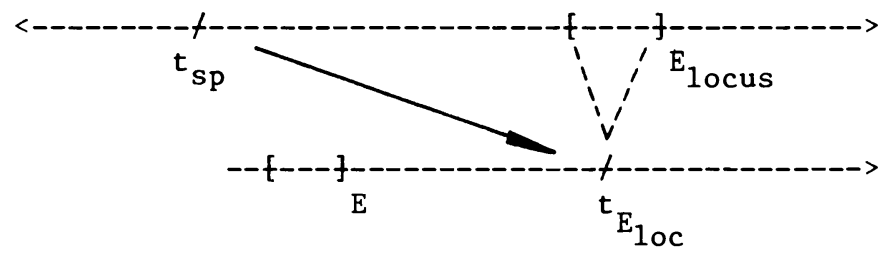

For the eastern Bantu languages it is my claim that the auxiliaries -ba and $-I i$ are grammatical vehicles for the indexing of this second event-locus 
and are referential in that they refer to a second locus. The "value" of the locus shifts according to context as a different event is indexed to serve as the event-locus. In order to support this claim I will present evidence that neither -ba nor $-\mathrm{l} i$ is simply a tense support and show that they do, in fact, index events from context. Finally $I$ will suggest how the two differ in those languages that employ both of them in the same types of complex constructions.

3. Evidence Against $-b a$ and $-1 i$ as Tense Supports

Conventional explanations of complex 'be' constructions have assumed, incorrectly, that the auxiliary verb, whether -ba or $-1 i$, simply serves to carry the tense marking for the construction. Evidence of usage from a number of languages argues against this assumption. Consider first some cases in which the tense marker on the auxiliary verb does not indicate the time of the event.

(1) Kinyarwanda ( $\mathrm{J}$ 61) [Botne 1981]

a. uza:garuke ejó kare, n-za:-ba n-â:-gi-som-ye

$2 \mathrm{~s}$-fut-return tomorrow early $1 \mathrm{~s}$-fut-be $1 \mathrm{~s}$-pst-7-read-comp

'come back early tomorrow, I'11 have read it (before then)'

b. Yohaní nli á:zana ibito:ke makúmyă:biri, n-ra-bá n-zla:-e:ng-a John if 3s-bring bananas twenty 1s-nfut-be 1s-fut-brew-perf

'if John would bring 20 bananas (today), I will brew (some beer) (after today)'

(2) Ciyao (P 21) [Whiteley 1966:214]

a. ngáli juvávééceeté sooní pélé-po

not-be rel-3s-speak-asp again that time (after)

tu-li tw-a-más-ilé góná

lp-be 1 p-pst-finish-asp sleep

'no one spoke again, that was after we had gone to sleep'

${ }^{1}$ Abbreviations used in the examples are:

$\begin{array}{llll}\mathrm{T} & =\text { tense marker } & \text { nfut }=\text { near future } & \text { perf }=\text { perfective } \\ \text { asp } & =\text { aspect marker } & \text { pst }=\text { past } & \text { pass }=\text { passive } \\ \text { fut }=\text { remote future } & \text { comp }=\text { completive } & \end{array}$


b. tw-a-lî-ji mkusyơómá bálúá katémá kámwapítágá-ko

1p-pst-be-? in-to read letter time 12-2p-pst-pass-asp-1oc

nímlole nganitumkólanga

that's-reason not-1p-2p-greet-asp

'we were reading a letter when you were passing, that's why we didn't greet you'

In Kinyarwanda the future is sub-divided into two phases, later today (marked by -ra-) and after today (marked by -za:-). In (1a) the reading of the book will occur before early tomorrow morning, hence today. Yet -ba is marked with the distant future marker -za:- , indicating after today. Clearly, the time of the event and the temporal phase indicated, specified by the tense marker on -ba, do not correspond. Similarly, in (1b) 'brewing' will occur after today, but auxiliary -ba is marked with -ra-, later today. Again we find a discrepancy in the time referred to by the tense marker and the time of the event. An analysis that assumes -ba to be simply a support for tense cannot explain this tense usage.

In the Ciyao examples $-1 i$ is covertly marked for non-future, the future marker being the prefix $t i-$ or tu- (the tu- in these examples being the 1st person plural marker and not the future). The overt tense marker for past, -a-, is found on the complement verb, and not on the auxiliary. Since $-1 \mathrm{i}$ can occur with the past marker, as shown in (2b), we need to consider why it does not do so in (2a), a case that would appear to warrant its occurrence. The fact that $-1 i$ may or may not take a particular tense marker strongly suggests that it is not an empty form serving to support tense morphemes, but rather that there are contextual factors which require the expression of certain temporal relations.

Another bit of evidence refuting the notion of "tense support" can be found in cases where both the auxiliary verb and the complement verb have the same tense marker, as in examples (3-5). If the auxiliary is truly only a tense support, then why should there be a need for two markers that have the same time reference? 
(3) Siswati (S 43) [Ziervogel and Mabuza 1976:187]

ba-tawu-be ba-tawu-cala nakuvakala kukhala inkwela

3 p-fut-be 3 p-fut-start when-to be audible to produce sound whistle

'they will be about to start when the whistle sounds'

(4) Kirundi ( $\mathrm{J}$ 61)

niya azaná ubwă:tsi bw'inzu, tu-zo:-ba tú-zo:-sáka:ra inzu

if 3 s-bring thatch of house 1 p-fut-be 1 p-fut-thatch house

'if he would bring the thatch (tomorrow), we will thatch the house (after tomorrow)'

(5) Lamba (M 54) [Doke 1938:305]

$n-\bar{a}-1 i \quad n-\bar{a}-m u-w o n a \quad|\bar{e}| o$

1s-pst-be 1s-pst-him-see today

'I have seen him today'

Note that for Siswati and Kirundi the complement verb is not restricted to the same tense marker as found on the auxiliary; other possibilities exist, as in $(6-7)$.

(6) Siswati [Ziervoge1 and Mabuza 1976:187]

$$
\begin{aligned}
& \text { ba-ta(wu)-be ba- } \varnothing \text {-nats-é inkantini, hhayi tjwala } \\
& 3 p-f u t-b e \quad 3 p-T-d r i n k-a s p 1 \text { iquor not beer } \\
& \text { 'they will have drunk liquor, not beer' }
\end{aligned}
$$

(7) Kirundi

ni wazá mukwe:zi kuúza tu-zo:-ba tw-â:-saka:-ye inzu

if $2 \mathrm{~s}$-come month to come $1 \mathrm{p}$-fut-be $1 \mathrm{p}$-pst-thatch-comp house

'if you come next month, we will have thatched the house'

These examples suggest that the complement verb is marked with respect to some locus other than the speech event, otherwise we would expect a past interpretation in (7). The presence of $-b a$ or $-1 \mathrm{i}$ and the appropriate tense affix signals the location of this other locus, hence the need for the tense marker on the auxiliary.

A final piece of evidence, and perhaps the most compelling, is found in imperative constructions. In these cases we find two possible constructions, one with auxiliary -ba and one without. Both have the same temporal mean- 
ing, yet they differ significantly in their implications.

(8) Cinyanja ( N 31) [Hetherwick 1914:149]

a. ba khala pansi pang'ono pano

be sit on ground a little here

'sit down on the ground for a little here (while I do something else)'

b. khala

'sit (down)!'

(9) Kinyarwanda [Botne 1983:259]
a. ba wi:caye hasí
be 2 s-sit-comp on ground
'sit down on the ground (while I do something else)'
b. icara
'sit (down)!'

From the parenthetical commentary in the (8a) and (9a) examples it is clear that the presence of -ba affects the meaning of the utterance over and above any notion of time. It is also clear that -ba does not carry any tense marker in the (a) examples that differentiates the complex construction from the simple one found in (b). Thus, -ba cannot be considered to be a meaningless, empty support element in a complex construction.

These few examples from a variety of eastern (and southern) languages are sufficient to demonstrate that the conventional assumptions about the roles of $-b a$ and $-1 i$ are incorrect and that there is much more to the functions of these auxiliaries than a tense support hypothesis can handle.

4. -ba and $-1 \mathrm{i}$ as Shifters

The tense support hypothesis, as we have seen, does not account for the observed occurrences of the complex 'be' constructions. In place of this hypothesis I propose that these auxiliaries are best treated as shifters, that is, as sign vehicles that have both referential and indexical functions. They refer to a second locus of orientation which, as part of the temporal framework, must be situated temporally with respect to the speech event. For 
this reason it is not surprising that the auxiliary verb may take a variety of tense markers, as would a main verb in simple constructions. The tense marker simply indicates the relationship between the primary locus (the speech event) and the secondary locus. That is, the tense marker indicates whether the time of the event-locus $\left(t_{E_{1}}\right)$ is anterior, posterior, or contemporaneous with $t_{\mathrm{sp}}$. The particular ${ }^{10 c}$ "value" of $\mathrm{t}_{\mathrm{E}_{10 \mathrm{c}}}$ is not specified by the auxiliary verb; rather, it comes from the context of the utterance. Thus, the value (or "meaning") of the auxiliary shifts according to the context and the exact event that it indexes as the locus.

There are, then, three properties of these complex 'be' constructions that are salient here: (1) they establish a second locus of orientation; (2) they index an event from context that serves as the "cognitive" value of the second locus referred to; and (3) they indicate that the event $E$ is to be interpreted directly with respect to this second event-locus ( $\left.\mathrm{E}_{1 \mathrm{loc}}\right)$. The first and third of these properties are interconnected; that is, if a second locus is grammatically established (by use of - ba or $-i i$ ), then $E$ must be interpreted with respect to this locus.

Consider explicitly how this works by comparing the two examples from Kirundi, repeated here as $(10 a)$ and (10b).

(10) Kirundi

a. niya azaná ubwă:tsi bw'ínzu, tu-zo:-ba tú-zo:-sáka:ra inzu if $3 \mathrm{~s}$-bring thatch of house $1 \mathrm{p}$-fut-be $1 \mathrm{p}$-fut-thatch house 'if he would bring the thatch (tomorrow), we will thatch the house (after tomorrow)'

b. ní wazá mukwe:zi kuúza tu-zo:-ba tw-â:-saka:-ye inzu if $2 \mathrm{~s}$-come month to come $1 \mathrm{p}$-fut-be $1 \mathrm{p}$-pst-thatch-comp house 'if you come next month, we will have thatched the house'

In both sentences the auxiliary -ba is marked by the remote future marker -zo:- , hence, the second locus of orientation has been situated posterior, and specifically after today, with respect to the time of the speech event. However, both the "value" attached to this locus, i.e. the event indexed, and the relationship of the event narrated in the complement clause to this second 
locus differ. In (10a) -ba indexes the event 'bring thatch', and it is with respect to this particular event that the actual thatching of the house will take place, specifically on some day after the day on which the thatch is brought, hence the use of $-z o:-$ on the complement verb. In (10b) -ba indexes 'come next month'; the past affixes, -a:- and -ye, on the complement verb indicate the temporal relationship of the event 'thatch house' with respect to this specific event. These two complex temporal frameworks can be represented schematically as shown in Figure 2.

How the narrated event is to be interpreted temporally with respect to the indexed locus is indicated by the affixes attached to the complement verb. In many cases this relationship will be determined in terms of aspectual distinctions, specifically, what aspect of the event $E$ is to be focused on with respect to the state of affairs at $t_{E_{10 c}}$. A few languages, such as Kirundi, maintain tense distinctions similar, if not identical, to those expressed between $E$ and $t_{s p}$ in simple constructions. Luganda (J15), Kiswahili (G42), and Siswati (S43) are illustrative of the aspect type, Kinyarwanda (J61) and Ciyao (P21) of the tense type.

(11) Luganda [Ashton et a1. 1954:292]

a. bwe nnamulaba, yali asoggola lumonde when 1s-pst-her-see 3s-pst-be 3s-dig up potatoes

'when I saw her, she was digging up potatoes'

b. bwe nnamulaba, yali alusoggoze

$$
\text { 3s-pst-be 3s-them-dig up-comp }
$$

'when I saw her, she had dug them (potatoes) up'

(12) Kiswahili [Ashton 1944:250, Wilson 1970:247]

a. hapo majajazi yalipokuwa yanatoka bandari,

then dhows 6-pst-when-be 6-pres-leave harbor

kulisikilizana kelele

17-pst-be heard noise

'just as the dhows were leaving the harbor, a noise was heard' 
Figure 2. Complex temporal frameworks in Kirundi

(10a)

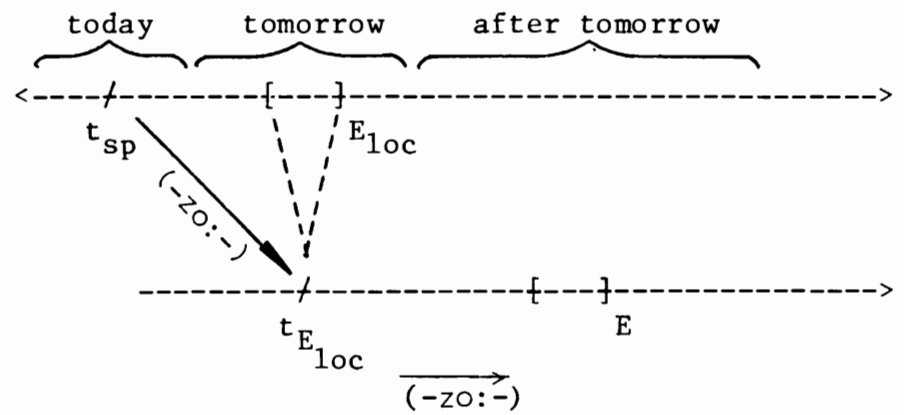

$t_{\text {sp }}=$ time of speech event

$\mathrm{t}_{\mathrm{E}_{1 \mathrm{oc}}}=\mathrm{t}$ ime of $\mathrm{E}_{1 \mathrm{oc}}$ indexed by -ba

$\mathrm{E}_{1 \mathrm{oc}}=$ bring thatch

$\mathrm{E}=$ thatch house

(10b)

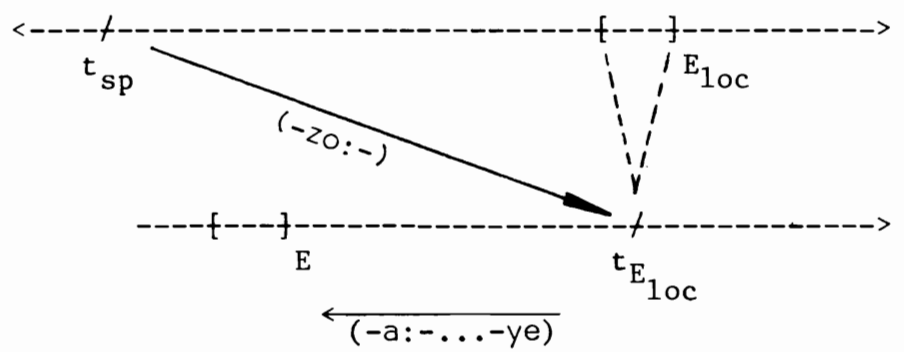

$t_{\mathrm{sp}}=$ time of speech event

$t_{E_{1 o c}}=$ time of $E_{1 o c}$ indexed by -ba

$\mathrm{E}_{1 \mathrm{oc}}=$ come next month

E = thatch house 
b. nilikasirika sana kwa sababu alikuwa akilala mkutanoni 1s-pst-be angry very because 3s-pst-be 3s-cont-sleep meeting-at 'I was very angry because he was sleeping at the meeting'

(13) Siswati [Ziervogel and Mabuza 1976:187]
a. batawube bahamba nabafikako bangani bakhe

3p-fut-be 3p-travel when-3p-arrive-loc friends his

'they will be traveling when his friends arrive'
b. batawube bahambile nabafikako bangani bakhe 3p-travel-comp

'they will have traveled (completed), when his friends arrive'

(14) Kinyarwanda [Botne 1981, 1983]
a. uza:garuke nímugóro:ba, ndabá
2s-fut-return evening 1s-nfut-be 1s-pst-it-brew-comp
'come back this evening, I will have brewed it (beer)'
b. n'â:zana ibito:ke, ndabá nze:nga urwâ:gwa
if-3s-bring bananas 1s-nfut-be $1 \bar{s}$-fut-brew banana beer
'if he would bring some bananas, I will brew some banana beer (after today)'

(15) Ciyao [Whiteley 1966:214]
a puváíkagá ambújé-wo uwé ní tuli
when-3s-arrive-asp grandfather-dem my 1 p-be
tumasílé kúl yá
lp-finish-asp to eat

'when my grandfather arrived we were finished eating'

b. ngáli juvávééceeté sooní pélé-po tuli

not-be rel-3s-speak-asp again that-when 1 p-be

twamásilé góná

1p-pst-finish-asp sleep

'no one spoke again, that was after we had gone to sleep'

From these data it should be apparent that both -ba and $-1 i$ play signifi-

cant roles in establishing one locus of the temporal framework in which the event is to be interpreted. How the event will be interpreted with respect to this locus depends on the type of tense/aspect system a particular lan- 
guage employs for these constructions. The nature of this system may depend, in part, on whether constructions are made with -ba or with $-1 \mathrm{i}$.

\section{Differentiating -ba and $-1 \mathrm{i}$}

We have seen that both $-b a$ and $-1 \mathbf{i}$ function to establish a second locus of orientation, but as yet there has been no indication of how they differ. Of the dozen or so languages examined five utilized both -ba and $-1 \mathrm{i}$ constructions. By comparing the sense of the two types of constructions in some of these languages we gain some sense of the difference in effect of using one or the other (and even both together) of the auxiliaries. Consider first the case of $-1 \mathrm{i}$ in some constructions that have locative complements (the (a) examples that follow):

(16) Kinyarwanda [Botne 1981, 1983]
a. ari mukwe: $n^{2} a^{2}$
3s-be in-to brew
'he's (in the midst of) brewing'
b. are:nga
3s-pres-brew
'he's brewing'

(17) Ciyao [Whiteley 1966]
a. túlí mkutává nyúmba Ip-be in-to build house
'we are (in the midst of) building a
b. tukútává nyúmba
Ip-pres-build house house'
'we are building a house'

(18) Cigogo (G 11)
a. nili mundya
1s-be in-eat
'I am (in the midst of) eating'
b. nkulya
1s-pres-eat
'I am eating'

While both the (a) and (b) examples can be used to speak of an event on-going at the time of the speech event, they differ subtly but significantly in their meanings. The $-1 i+$ locative constructions (either mu- or m- plus

${ }^{2}$ In Kinyarwanda the suppletive form of 'be', $-1 i$, is realized as $-r i$ except after a nasal such as the first person singular subject marker $n-$, where we find ndi. 
infinitive) indicate that at the moment of speaking the speaker is actually engaged physically in the event that is being described. On the other hand, the examples in (b) are all "general" present tenses indicating that the subject is involved in the named event, but it is not the case that the subject is necessarily actually performing the activity (he may be resting, for example). Hence, the use of $-1 \mathrm{i}$ picks out a particular moment in the event for focus.

This role of $-1 i$ is even more apparent in a construction like that found in Kinyarwanda in which the locative construction occurs as the sentential complement of $-r i$.

(19) Kinyarwanda [Botne 1981]

Gasaná azá, narí ndi mukwe:nga, nyumá arakazwa

Gasana 3s-come 1s-pst-be 1s-be in-to brew then 3s-be angry-pass

n'û:ko ntă:muramukije

it's because neg-3s-pst-him-greet-comp

'when Gasana came I was in the midst of brewing; he became angry because I didn't greet him properly (at that moment)'

At a particular moment in the past the speaker was engaged in brewing beer, which involves mashing up bananas with the hands. He was not able to greet Gasana properly, i.e. by embracing him with both arms, at the moment of arriva1 because he was occupied.

This "punctual" nature of the $-1 i$ construction can be contrasted direct1y with the same locative type construction in -ba. Consider the following example from Ciyao, and compare it with the example in (17a).

(20) Ciyao [Whiteley 1966:190]

túv'é mkutává nyúmba ni tááce kútukámúsya

$1 \mathrm{p}$-be in-to build house and fut-3s-come to-us-help

'we will be building a house (w/implication of continuity) and he'11 come and help us'

Here we find a durative, continuous notion ascribed to the event 'build', whereas in (17a) the $-1 \mathrm{i}$ construction picks out and focuses on a particular moment of the event. This "durative/momentaneous" opposition is found not on- 
$1 y$ in these 'be' + locative constructions, but also in the 'be' + sentential complement constructions. A clear distinction can be observed in Kinyarwanda where we find $-b a$ and $-1 i$ constructions opposed in the past tense.

(21) Kinyarwanda [Botne 1981]

$$
\begin{aligned}
& \text { a. nabâ:ye nǐga ntégereje Mihigo } \\
& \text { 1s-pst-be-comp ls-study } 1 \text { s-wait-comp Mihigo } \\
& \text { 'I studied while waiting for Mihigo' }
\end{aligned}
$$

b. ukó umugoré wé yaréraga umuhǔ:ngu wâ:bo while wife his 3s-pst-tend-impf son their yabága $\quad y \hat{\imath}: g a \quad k u ́ r i$ iniversite 3s-pst-be-impf $3 s$-study at university 'while his wife was caring for their son, he studied at the university'

$$
\begin{aligned}
& \text { c. nári nîze mbere yó kubónana na mwâ: limú } \\
& \text { 1s-pst-be 1s-study-comp before to meet with teacher } \\
& \text { 'I had studied before seeing the teacher' }
\end{aligned}
$$

The -ba auxiliary, unlike -ri, can be marked for quantitative aspect, that is whether or not the event-locus represents a single instantiation of the situation or multiple occurrences. In (21a) we find the former, in (21b) the latter. In both instances there is emphasis on the fact that the situation occurred over a period of time. In (21c) there is no indication of an interval or of duration of the event; rather, the event is treated as a whole with no indication of its temporal dimension.

These constructions with $-r i$ always appear to have the sense of "E occurs before a point $\mathrm{t}_{\mathrm{E}_{10 \mathrm{c}}}$ " or "a moment in $\mathrm{E}$ ". In effect, we might say that $-r i$ indexes a loc particular critical moment in the relationship of events spoken of and, hence, might be considered to index a temporal juncture. By contrast, -ba constructions appear to emphasize the durative, continuous nature of the situation.

\section{Summary and Some Conclusions}

I hope, in this brief paper, to have provided evidence against the view that $-b a$ and $-1 i$ are semantically empty morphemes and in favor of the 
view that they serve an important temporal function. I have argued that they have a dual function. They are referential in that they refer to a second 1ocus of orientation and indexical in that they index an event from context. This dual function suggests that they are best treated as shifters, in much the same way as, for example, demonstrative pronouns. The dual nature of these two verbs can be visualized as the figure below suggests.

Figure 3. Function of $-\mathrm{ba}$ and $-1 \mathrm{i}$

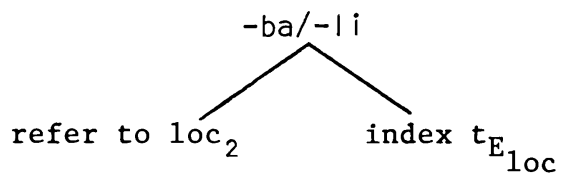

(The value associated with $10 c_{2}$ depends on the pragmatic value of $\mathrm{t}_{\mathrm{E}}$, i.e. on what is indexed as the locus.)

The perspective $I$ have presented here of - ba and $-1 i$ as referential indices provides the basis for explaining much of the semantic and pragmatic behavior of complex "be" expressions throughout the eastern Bantu region. In particular, it explains how temporal relations among several events are indicated grammatically and suggests how and why they come to be used at a particular point in discourse.

I have explored here some of the aspects of meaning of the auxiliaries -ba and $-l i$. If we are to come to some fuller understanding of temporal modalities as expressed in such complex constructions as these "be" constructions we need to explore more closely the uses of the many other auxiliary verbs found in these languages. And we need to be wary of passing off various elements as "empty" or "meaningless", for it may simply be that we have failed to observe the subtle roles they may play. 


\section{REFERENCES}

Ashton, E.0. 1976. Swahili Grammar. London: Longman Group.

Ashton, E.0. et al. 1954. A Luganda Grammar. London: Longmans, Green \& Co.

Botne, Robert. 1981. "On the nature of tense and aspect: studies in the semantics of temporal reference in English and Kinyarwanda." Unpublished PhD Dissertation, Northwestern University.

Botne, Robert. 1983. "The semantics of tense in Kinyarwanda." Studies in African Linguistics 14:235-263.

Doke, Clement M. 1938. Textbook of Lamba Grammar. Johannesburg: Witwatersrand University Press.

Hetherwick, Rev. Alexander. 1914. A Practical Manual of the Nyanja Language. Nyasaland and Northern Rhodesia: African Lakes Corporation, Ltd.

Whiteley, W.H. 1966. A Study of Yao Sentences. Oxford: Clarendon Press.

Wilson, P.M. 1970. Simplified Swahili. Nairobi: East African Literature Bureau.

Ziervogel, D. and E.J. Mabuza. 1976. A Grammar of the Swati Language (Siswati). Pretoria: J.L. Van Schaik Limited. 
